\title{
Wind and Solar Energy Resources Potential across Coastal Mega Cities, of Pakistan
}

\author{
Sabir Ali Kalhoro, Muhammad Shahid, Syed M. Usman Ali, Engr. Tufail Ahmed, Darakhshan \\ Ara
}

\begin{abstract}
Pakistan has the vast potential of renewable energy (RE) resources but still, rely on the pricy fossil fuel-based power generation. The developed nation work on the shifting of conventional resources based generation into renewable energy-based generation, but Pakistan still engages to negotiate fossil fuel trade. However, Pakistan has $1100 \mathrm{Km}$ of the coastal belt that acquires the huge potential of RE. The different metrological department measure the RE exists in Pakistan, the World Bank Group is one of them. The World Bank group observe the solar and wind potential across the megacity of Pakistan including Karachi. In this research, we have explored the World Bank efforts by highlighting the availability of the solar and wind power across coastal megacity, of Pakistan. The main focus is on the estimates of global horizontal irradiation (GHI) parameter of solar and wind speed for wind resources along with the yearly values provided by the World Bank.

The wind power depend on wind speed across so, in this research, the wind speed is observed across the coastal megacity of Pakistan for the wind turbine installation. The wind speed data is occupied from the World Bank site to explore wind model for the future power supply across Karachi of Pakistan. Similarly, the solar irradiation calculation is very much important to install solar models. So we have select the GHI for the solar observation across Karachi of Pakistan. The GHI data is taken from the World Bank site and exploring on excel to find the future power generation across coastal megacity of Pakistan. Both wind speed and GHI parameter are observed by a yearly basis. It is detected that the regular trend for each of the selected years is related to the next year so the perceived trend of GHI and wind speed is valid for the upcoming year. Hence the GHI and wind speed availability indicate the installation of solar penal and wind turbine for the power generation across the coastal megacity of Pakistan. The GHI and wind speed experimental data for the coastal megacity contain a huge amount of solar and wind potential. The planner needs to explore this energy by installing a suitable quantity of the solar plant and windmills for power generation.
\end{abstract}

Keywords: GHI; Wind Speed; Renewable Energy; World Bank.

\section{INTRODUCTION}

Electricity is the backbone for economic and viable development growth of any country. Buyers continuously

Revised Version Manuscript Received on August 19, 2019.

Sabir Ali Kalhoro, Department of Electronics Engineering NED University of Engineering and Technology Karachi Pakistan(email: Sabir13es66@gmail.com)

Muhammad Shahid, Dawood University of Engineering \& Technology, Karachi, Pakistan (email: engr_shahid82@ yahoo.com)

Syed M. Usman Ali, Department of Electronics Engineering NED University of Engineering and Technology Karachi Pakistan(email: uashah68@neduet.edu.pk)

Engr. Tufail Ahmed, Department of Electronics Engineering, Mehran University of Engineering and Technology Jamshoro, Pakistan(email: Tufail.waseer@faculty.muet.edu.pk)

Darakhshan Ara, Dawood University of Engineering \& Technology, Karachi, Pakistan (email: ara.chemistry@yahoo.com) demand consistent and low price of electricity. The unfortunate power responsibility affects the buyers so the economical rustic is continued in the country. [1-3].

Energy has remained the attention of the many social, political and economic debates in the Islamic Republic of Pakistan. For many years, the problem of energy shortage does not meet any reliable solutions. Instead, the problem has intensified as, the rapid urbanization and population growth result spiral demand for energy. So, the electrical blackouts caused by numerous load-shedding that have additionally partner within the kind of fossil fuel bargain.

Energy can be a play a key significant role for the common industrial demand. Energy offers a vital ingredient for handsome social activities. The energy delivery facilities for home economics, industrial production, and transport. In energy supplier has been accomplished a robust economic and social development, to improve abundant access to electricity services to the residents. But traditionally, Pakistan has been associate in uncontrollable energy deficient country. It's relied virtually upon fossil fuels that are the key source of electricity production. Remaining to the aggressive economy and population, the demand for energy is speedily increasing. Pakistan is at risk of facing vast energy deficits within the coming back years and even at the moment, the first energy supplier doesn't meet the primary demand incorrect manner [4-9].

Pakistan needs to increase the uses of renewable energy (RE) sources, which is able to fulfill the gap of energy deficiency. Pakistan's energy crisis will be reduced by employing RE as well as different other freely available sources of energy. The rich sources of RE are solar, wind, tidal, geothermal, biomass, hydro and thermal. The RE has the potential to exchange fossil fuels within the future due to the power potential and its eco-friendly factors. In this regard, the imperative awareness efforts are indicated toward the RE. $\mathrm{RE}$ resources are key to success for Pakistan as a developing economy nation [9-11].

Pakistan must exploit the offered RE sources to reduce the energy shortage that gives energy crisis and anxiety among the user. So the energy required to support the local, industrial and transport is basically needed for the economic growth of the country. The economic progress of Pakistan must be developed by improving the RE utilization that shaping the economy of the country [12-13]. 
The additional power requirement of the industrial developments similarly as satisfying the business, logistics and domestic localities. So the country has already the various potential of RE out there in Pakistan. But solar and the wind is highly supportive for electricity production only need to work on that. They have the potential of producing numerous power only need to explore it. The variety of reviews are revealed the RE supply and usage in Pakistan, but no definite study has been centered RE usage for power generation.

Several nations have developed their energy roadmap, and if Pakistan should follow suit it's solely possible method then country became energy-rich.

The fundamental data of World Bank by wind and solar put long effectiveness across Pakistan. The RE gives clean and cheap energy supply expeditiously different coastal and non-coastal cities of Pakistan. This text can discuss first the standing outlook of wind energy use than highlighting the solar potential across Pakistan. The subsequent sections describe geographically localization of country, in existing energy scenario for wind energy use within the country [13-16].

It is often exposed that the country contains an enormous wind potential accessible. The coastal megacity of Pakistan specifies the favorable wind energy potential of $50,000 \mathrm{MW}$ with $7 \mathrm{~m} / \mathrm{s}$ of wind speed at $80 \mathrm{~m}$ altitude.

The wind map developed by National RE Laboratory (NREL), USA has indicated the supply of 346,000MW wind potential in Pakistan. The general wind corridors out there in Pakistan will offer abundant energy solution. Pakistan is a windy country whose coastal region have high wind potential to fulfill the country energy demand. The country has great wind space in the Sindh province, that features a terribly currently provide high wind potential over Pakistan. Such a large potential might be utilized to satisfy the native power shortage within the country. The high power scenario in Karachi like alternative apart but still the country is additionally terribly energy poor [16-19].

The World Bank and International Finance Corporation put together a cluster to provide the world solar Atlas worldwide for effective measurement of the real-time solar and wind resources. The atlas gives the regional information to support the wind and solar energy potential in countries.

The World Bank-supported and initiative the RE Resource mapping that structures the solar and wind. The World Bank Group has exclusive Solargis that is a world supplier of solar information and connects solar power assessment services. This world solar Atlas has been ready by Solargis underneath a contract to the World Bank, supported solar resource information that they own and maintain.

The aim the world solar atlas is to supply fast and straight access to solar resource data globally through the internet.

The sun is a major source of solar energy that supplies unlimited free energy. Presently, many tools are being hired to get electricity by the gathered solar system.

The unconventional energy has the capability to fulfill the world's electricity requirement. Because of only solar and wind energy. However additionally solar and wind resources are available along with the necessary consideration. The solar power might eventually be depleted in every of the most effective location to fulfill future energy demand.
The solar energy is superior in terms of availableness, price effectiveness, accessibility, capacity, and potency compared to other alternative RE sources.

Solar energy technologies became fixed and standard tool all over the world. To realize this, billions of people are capable to beat the present limits within the solar trade.

The solar business ought to focus a lot on the standard and development of its technology. Hopefully, a lot of analysis efforts are going to be dedicated toward PV technologies within the close to future to boost the stability and availability in the costs of solar modules.

The electrical energy created by penal depends on many external factors. Foremost of those is that the quantity of irradiation falling on the surface of the PV modules, that successively depends on the climate. If irradiation were the sole parameter influencing of power output [19-25].

The temperature may be a crucial secondary part. The different losses, like snow, dirt, dust, and longer-term dirtying effects rely mainly on environmental factors and improvement of the PV modules surface throughout the ability plant period.

The RE business, as well as a local generation by sensible measurement of such RE, will be adopted from World Bank analysis to clarify the magnitude of various varieties of solar and wind resource. The special thanks to the actual fact that objective proof concerning the accuracy of the models exists solely at a restricted range of World Bank sites worldwide. The RE resources availability in regard of location is usually examined by the World Bank group, therefore the chance to estimate the RE availability through the obtained data of the World Bank usually related to the megacity of Pakistan.

The research discusses the uncertainty analysis of the models used for the calculation of solar and wind resource by parameters. The main focus is on the estimates of global horizontal irradiation (GHI) parameter of solar and wind speed of wind resources along with the yearly values provided by the World Bank. The solar parameter GHI play a significant role for the solar penal installation similarly the wind speed calculation is important for the installation of the windmill across coastal megacity, of Pakistan. By observation of this research, the planner needs to installation the RE project for the power generation in the coastal megacity due to abundant availability of the solar and wind energy resources. Users will realize any technical details concerning the uncertainty of the models and weather variability by this research. The GHI and wind speed parameter concern by weather-related measurements of solar and wind resources potential.

The uncertainty of the long-run yearly resource estimates by satellite-based models may be characterized by scheming the systematic deviation for solar and wind measurements on the World Bank data [25-28]. 


\section{MODEL}

\subsection{Solar Model}

A modern scientific analytical model utilizes accumulation of scientific resources, utilizing the World Atlas providing specific information regarding the location. The Atlas data additional utilizes three main methodologies each assessing different parameters of solar energy: solar radiation model, air temperature model and PV power simulation model. These models provide location-specific solar irradiation and temperature data. In order to calculate an on-demand utility by assessing the possible PV system type and configuration of the PV power simulation models are employed.

The ground sensors mounted at satellite-based earth science. The two main approaches for getting solar resource information measurement the complementary. The high accuracy of ground-mounted solar sensors are used to measure the high frequency with high accuracy. Generally, the high accuracy and reliable information from solar sensors measure by the specific reliable station at the calculated locations. The advantage of the satellite-based models is that they incessantly represent a history depending on the regional potential.

The measurements by ground sensors facilitate the scale of uncertainty values, whereas irradiation models reciprocally offer an economical means of dominant standard measurements conducted by the stations. Also, the operational alternative energy comes, use satellite-based models to explore the solar resource potential. The information stages the project lifecycle and at an equivalent time to put in ground-mounted weather stations next to existing or planned large-scale project sites.

The solar uncertainty and managing weather associated risk is crucial for productive coming up with and dynamic solar electricity generation assets. In this Atlas, the foremost reliable sources of knowledge are obtained for the accumulation of the electricity that is used for the supporting policy development of the solar project.

\subsubsection{Solar radiation model}

The principal climate phenomena accomplish the solar power generation are represented by these parameter models. These technologies analyze GHI consisting of irradiation on the surface of PV sections. The World Bank uses to find out each parameter related to the solar availability in each region of the installed station. The solar parameters are explored to found for the evaluation of the solar energy in Pakistan. The parameter is global horizontal irradiation (GHI), direct normal irradiation (DNI), direct horizontal irradiation (DHI), and Temperature in the way of actual usage of the solar energy.

The strategies employed in the model calculation take into consideration the attenuation factors of radiation on the approach through the atmosphere until reaching the bottom surface. To calculate the solar resource parameters, the Solargis model uses knowledge inputs from fixed satellites models. First, clear-sky irradiance is being calculated. The clear-sky model, that considers the position of the sun at vapor content, the concentration of aerosols and ozone. Second, the fixed meteorological satellites are employed to measure the attenuation influence of clouds by the cloud index calculation. The clear-sky irradiance calculated the cloud index to regain the all-sky irradiance values. The horizontal irradiance is additional post-processed by different models to urge global and direct irradiance on inclined surfaces as shown in Eq.1-3.

$$
\begin{aligned}
& G H I=D H I+D N I \cdot \cos (\theta) \ldots \ldots \ldots \ldots \ldots \ldots \ldots \ldots \ldots \ldots \ldots \ldots \ldots \ldots \ldots \ldots
\end{aligned}
$$

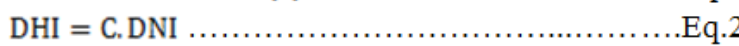

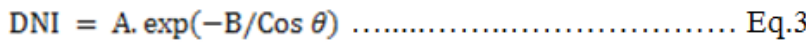

The elevation angle optimize the site show for the solar power coordination. The angle of elevation is measured as described in Eq.4. When we subtract the $90^{\circ}$ from the elevation angle the result find the zenith angle as shown in Eq.5.

$$
\begin{array}{r}
\operatorname{Cos} \theta=\sin \delta \sin \varphi+\operatorname{Cos} \delta \operatorname{Cos} \varphi \cos \omega \ldots \ldots \ldots \ldots \ldots \ldots \ldots \ldots \ldots \ldots \ldots \ldots \ldots \ldots \ldots \ldots \ldots \ldots \ldots \ldots \ldots \ldots \ldots \ldots \ldots \ldots \ldots \ldots \\
\zeta=90
\end{array}
$$

These whole parameter were observed by the World Bank group but here we have done the focus on the GHI because it is a climate reference use to enables the place for observation as mention in Eq.1.

\subsubsection{Solargis solar resource data}

The uncertainty of the long-term yearly solar resource estimates by satellite-based models can be characterized by calculating the systematic deviation at the validation sites, where high-quality solar measurements are available. An analysis of the distribution of the Solargis model systematic deviations in different geographies expected deviation in a range of $4 \%$ to $8 \%$ for GHI and $8 \%$ to $15 \%$ for DNI. A higher deviation is expected in purely difficult circumstances, and in areas which are not satisfactorily protected by weather-related measurements.

\subsubsection{Availability of solar resource validation sites}

The Solargis model has been validated using solar measurement data from 200 locations global. The stations access measurements of the different solar parameter in many regions. The uncertainty of solar irradiation models can be reduced by adding further permanent meteorological stations that incorporate high-quality solar measurement equipment or commissioning targeted solar measurement campaigns.

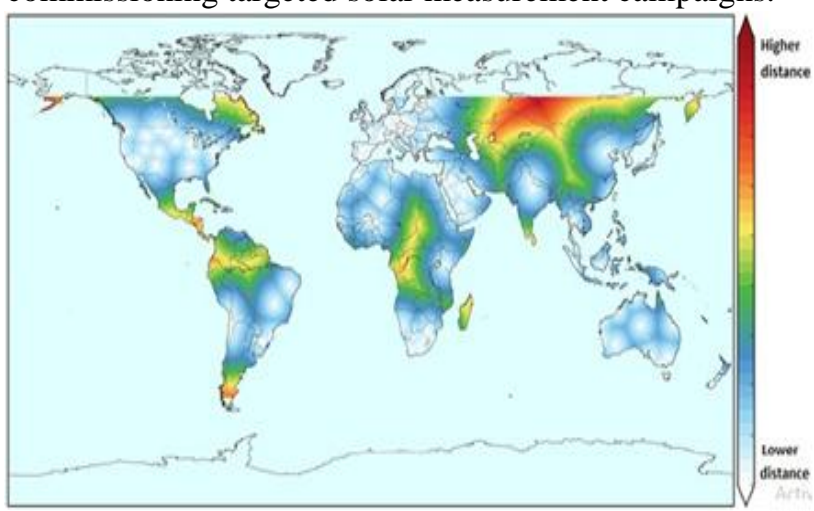

Fig.1. Distance to high-quality solar measuring stations used in the current validation of the Solargis solar radiation model. Picture Sources: World Bank Group Site. 


\subsection{Wind Models}

The wind energy can explore the door of power production from the wind speed by utilizing it. Energy, in a large manner, can be generated by wind resources exploration. The wind vitalities of the coastal megacity have been explored by the use of World Bank data. The World Bank uses the different parameter for the wind energy observation across Karachi of Pakistan. The parameter includes wind speed, minimum, and maximum, wind deviation and means wind speed. Here we get only wind speed for the wind power assessment across the coastal megacity, of Pakistan. The Parameter related to the wind power generation from the wind is shown in the Eq.6-8.

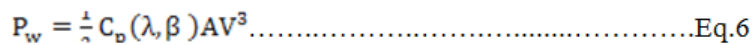

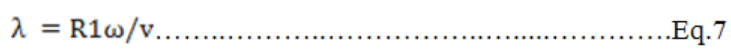

$$
\begin{aligned}
& \mathrm{Q}_{\omega}=\mathrm{P} \times \mathrm{Time}[\mathrm{KWh}]
\end{aligned}
$$

\subsubsection{Calculation of wind climates}

It is in this modeling application that the generalized wind climates provide local wind climates for every $1000 \mathrm{~m}$. To run the modeling over the very large area, a system of software and servers called the GWA Frog foot was developed. The flow modeling for orography, deviousness changes in a figure of ways to allow selected area.

\subsubsection{Accuracy of Data}

The location map-based data provided in the models suffer from challenges. One such challenge is the level of accuracy provided by the models utilized for assessment. The inaccuracy in the meteorological data may be minimized. The accuracy of the Meteorological models is typically estimated by comparing them to data from high-quality and well-managed meteorological measurements. To quantify the match between modeled and measured data statistical measures are used, characterizing systematic and random deviation as well as the representativeness of the distribution of hourly values. In such a comparison the imperfections of the models, the model input data, and the ground measurements are considered. In addition, weather variability over a longer timescale has to be considered in a complete assessment of weather risks related to solar energy technology.

\subsubsection{Validation}

The validation is a challenge where there are measurements, validation is possible at these localities. The measurements need to be of very high quality following guidelines of best practices for wind energy. The measurements need to be accompanied by an assessment of the site. It is possible to compare the generalized wind climate derived from measurements with that derived from the mesoscale simulations. It is also possible to downscale the generalized wind climate derived from the mesoscale simulations to give the predicted wind climate at the measurement site and compare this with the measured.

\section{EXPERIMENTATION}

The World Bank classifies and commissions the assignment on calculating the solar and wind energy potential of Pakistan. The World Bank has fitted the wind-solar masts for the power potential measurement across the coastal megacity of Pakistan. The project is fitted at the industrial department of the NED University Karachi.

The typical wind and solar measurements site processes the data as per each block in the wind and solar site functions.

The stations are put in gather for high accuracy solar irradiance and wind speed knowledge to change the improvement and validation of the renewable resources models. The model is going to be regenerated and valid against the measured knowledge, leading to the solar resource maps with a lower level of uncertainty. This method helps scale back the resource risk facing solar project developers, probably leading to lower prices and better quality comes.

For solar each location specifies the data provided by the Atlas involves three main completely different methodologies: irradiation model, air temperature model, and PV power simulation model. The irradiation and air temperature modeling end in a series of pre-calculated knowledge layers which will be retrieved at any location on the map. Extra data a couple of potential PV system sort and configuration is employed for the PV power simulation that is calculated on-demand exploitation Solargis internal algorithms and databases.

In the text on this web site the terms solar resource or radiation are substituted by two terms:

(i) Solar irradiance, denoting flux (power) per unit area, with typical unit $\mathrm{W} / \mathrm{m} 2$.

(ii) Solar irradiation, denoting energy or integral of solar irradiance over time, with typical unit W/m2.

The text below provides a summary of the introductory data. For a lot of complete description of the modeling approaches and connected uncertainties as refer fig. 2 .

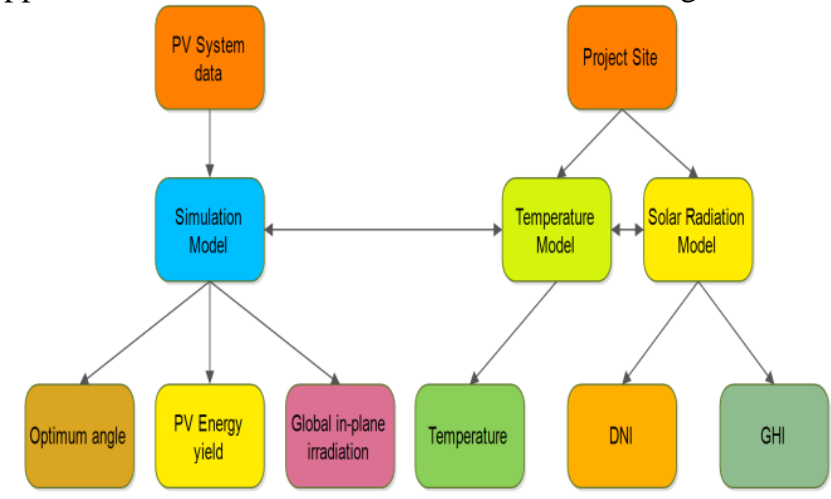

Fig.2. The Solar experimental model for the solar irradiation. Analysis Source: World Bank Group Site.

The uncertainty of radiation models is often reduced by adding any permanent brilliant stations that incorporate top-quality solar measure instrumentality, or authorization targeted solar measure campaigns because the UN agency cluster is already doing in many countries. Once a representative amount of ground measurements is noninheritable from new validation sites, managing the weather-related risk for development of recent solar power assets becomes easier. 


\section{RESULT}

The wind speed was calculated on the basis of World Bank data for yearly durations of 2015-2017. In each piece of observation, the data examined on the basis of the available World Bank calculation as shown in the fig.7-13. Every figure is based upon the wind speed available for the coastal megacity of Pakistan throughout the duration of 2015-2017. The wind speed in each study is being clearly concerned with the wind availability across Karachi. In the observation of each year, we will find the concerning trend for the future estimate of wind speed in the Karachi.

The World Bank group place calculated data of each year for all the researcher and give access to find out the calculation based upon the wind speed across the coastal megacity of Pakistan. The wind speed is observation from April to December of 2015 as shown in the fig.3. The wind data is being calculated from April of 2015 by the World Bank group so we observe data from April to December of 2015. Wind speed is scrutiny for the next year of calculated data as from January to June of 2016 as refer Fig.4. The data of 2016 is being observed into two-part due to excel is unable to take huge data first from January to June as above observation and second from July to December of 2016 as shown in fig.5. Also, the wind speed was studied for the third year of World Bank data sets in 2017. In 2017 the World Bank conduct the data from January to April so the trend is planned based on existing data observed. The wind speed reflection from January to April of 2017 is visible in the fig.6. The variation in the data shows the wind speed accessibility wind is available.

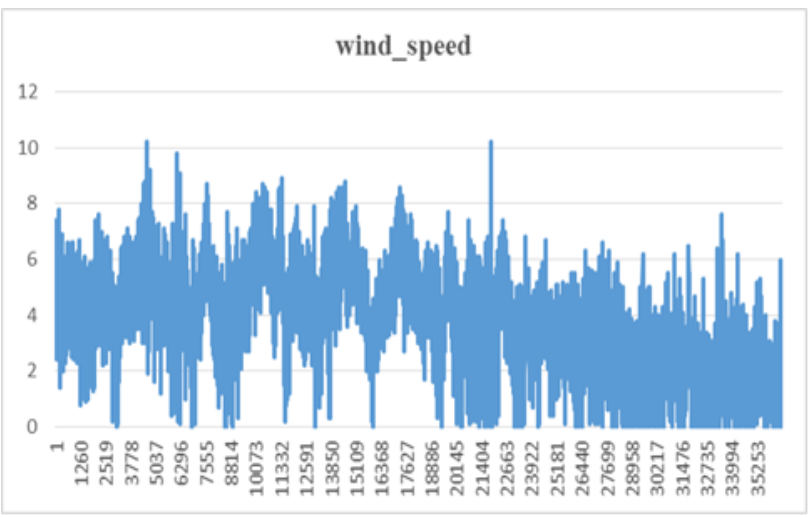

Fig.3. Wind Speed observation from April to December of 2015

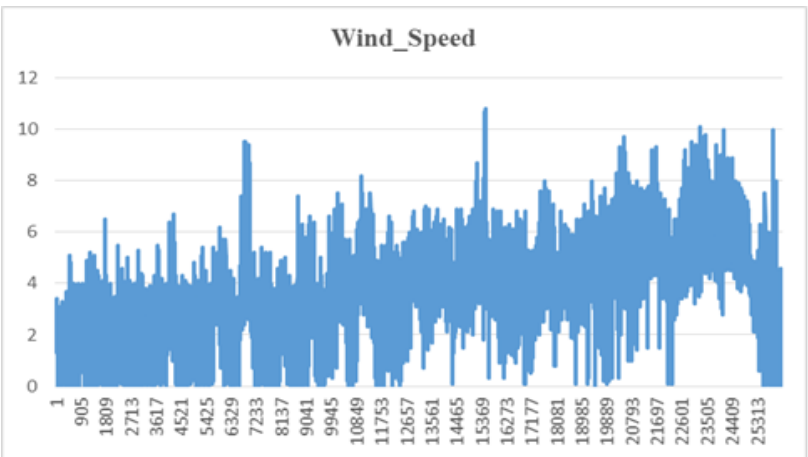

Fig.4. Wind Speed observation from January to June of 2016

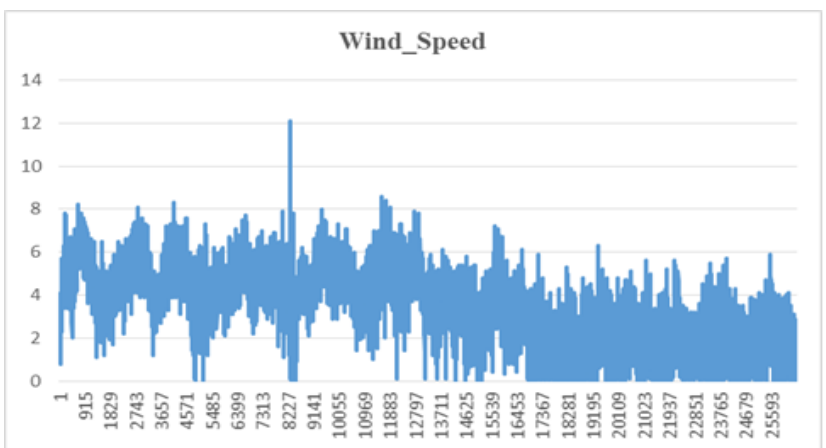

Fig.5. Wind Speed observation from July to December of 2016

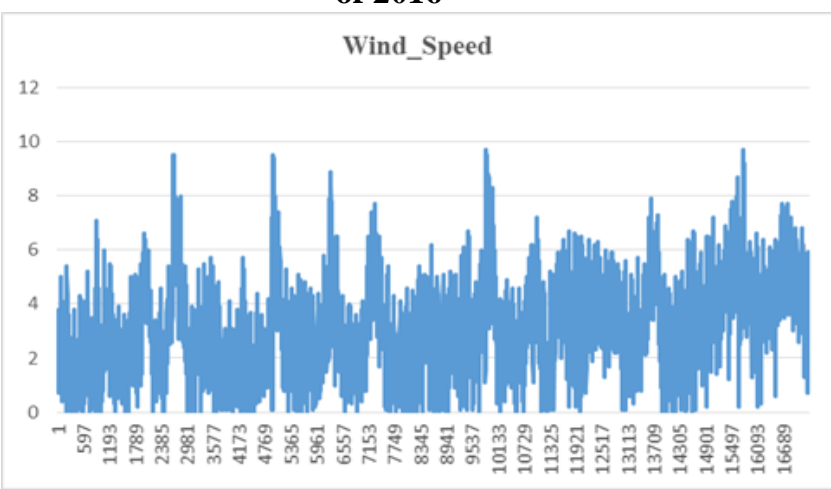

Fig.6. Wind Speed observation from January to April of 2017

The solar global horizontal irradiation (GHI) was studied for yearly durations of 2015-2017. In each section, the data were analyzed on the basis of the available data by the World Bank as shown in the fig.7-13. Each figure is based upon the GHI irradiation availability for the Karachi throughout the duration of 2015-2017. The GHI in each study is being clearly seen that the uniform sunny days are concerned. In the yearly trend of each year is concerned the future estimate of GHI irradiation.

The data is acquired from World Bank sites for the calculation of solar availability across coastal megacity of Pakistan [47]. The solar irradiation (GHI) is observation from April to December of 2015 as shown in the fig.7. Here the solar data is being calculated from April of 2015 by the World Bank group so we observe data from April to December of 2015. Solar Irradiation (GHI) is observed for the next year of calculated data as from January to June of 2016 as refer Fig.8. The data of 2016 is being observed into two-part due to excel is unable to take huge data first from January to June as above observation and second from July to December of 2016 as shown in fig.9. Also, the solar data was studied for the third year of World Bank data sets in 2017. In 2017 the World Bank conducts the data from January to April so the trend is premeditated based on existing data observed. The solar irradiation (GHI) observation from January to April of 2017 is exposed in the fig.10. The fluctuation in the observed data show the GHI availability as for as sunshiny is concerned. So due to the observed variation in data of each 10-minute, we have taken the average data of each month for 
a statement. The average GHI of each Month of 2015-2017 is observed in the fig.11-13.

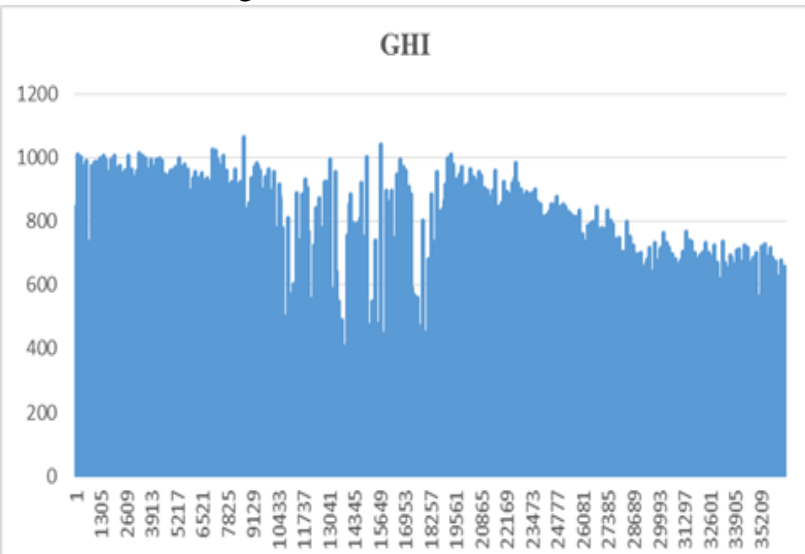

Fig.7. Solar Irradiation (GHI) Observation from April to December of 2015

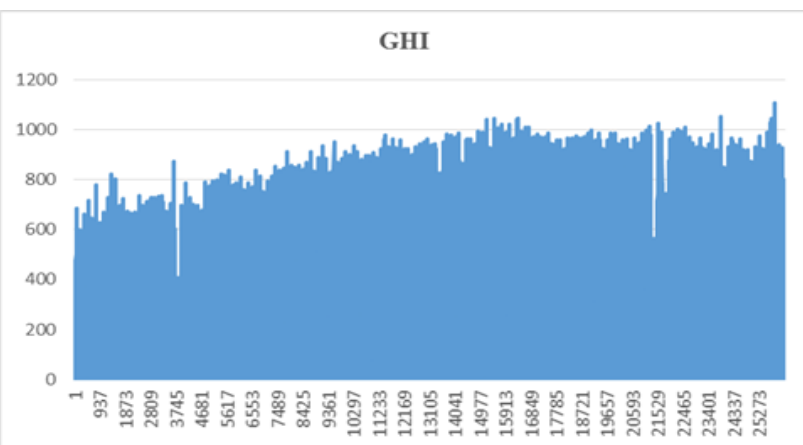

Fig.8. Solar Irradiation (GHI) observation from January to June of 2016

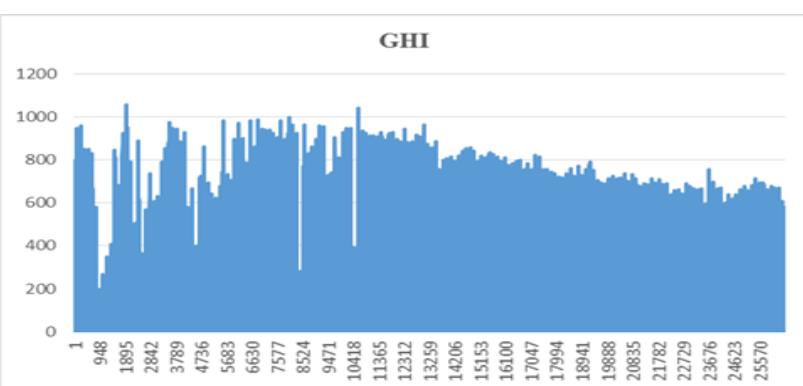

Fig.9. Solar Irradiation (GHI) observation from July to December of 2016

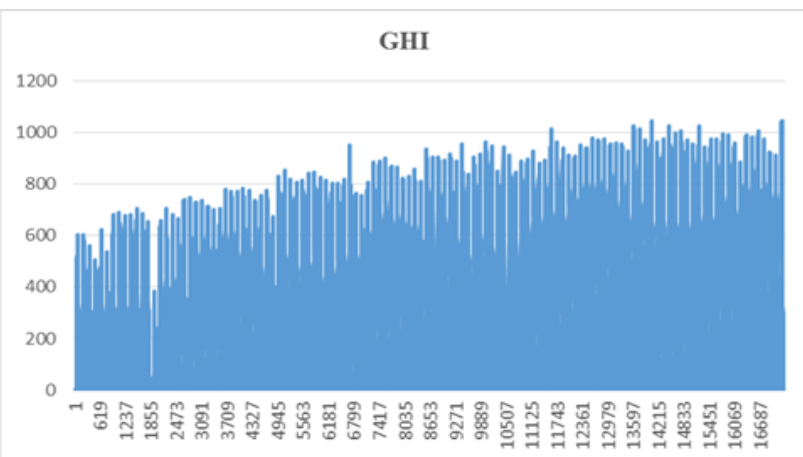

Fig.10. Solar Irradiation (GHI) observation from January to April of 2017

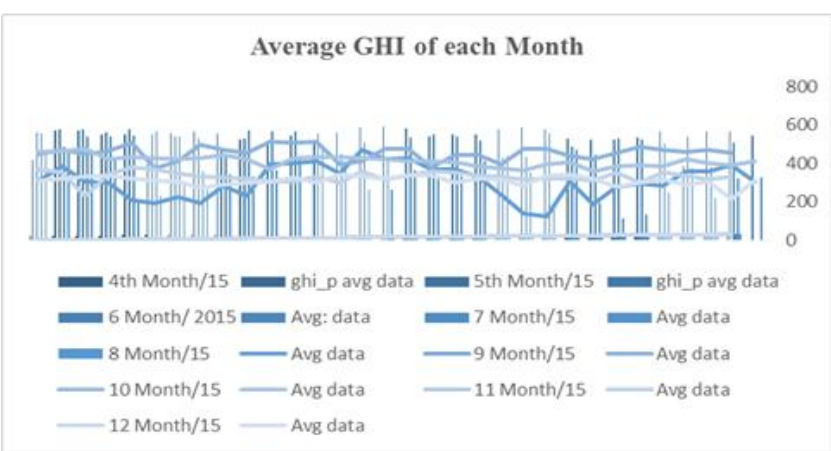

Fig.11. Average GHI of each Month of 2015 is observed

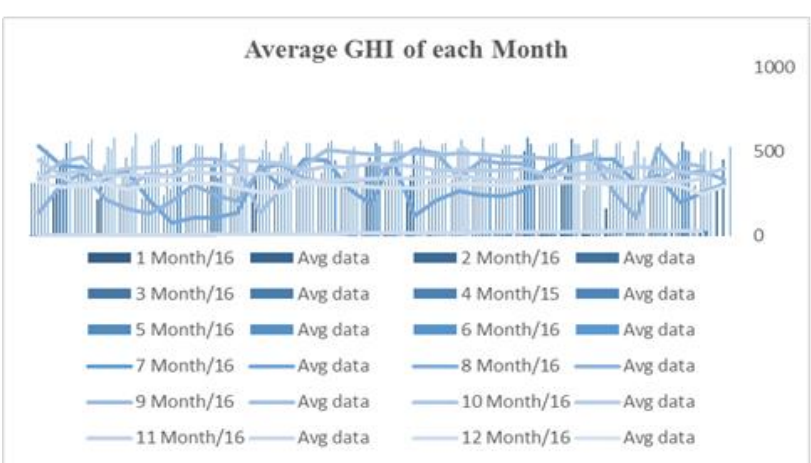

Fig.12. Average GHI of each Month of 2016 is observed

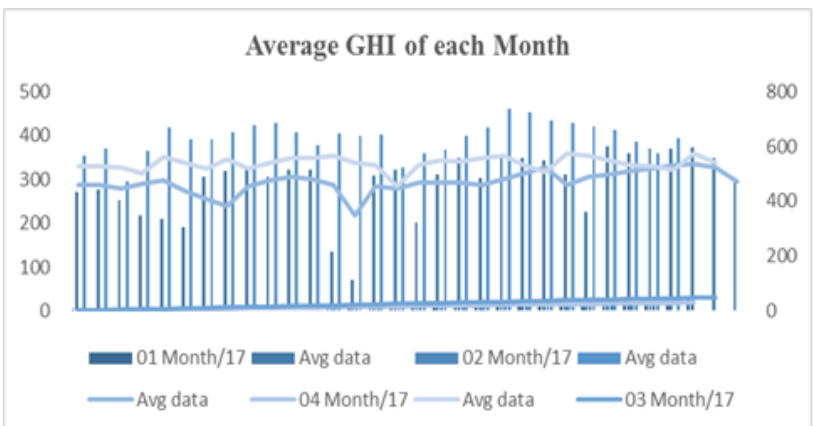

Fig.13. Average GHI of each Month of 2017 is observed

\section{DISCUSSION AND ANALYSIS}

The accuracy of the models is often calculable by the information from high-quality and well-managed parameter measurements. In such a comparison, the inadequacies of the models measure thought-out 2015-2017. Additionally, weather inconsistency over an extended timescale must be completely assessed by weather risks associated with the solar and wind tools.

The wind speed basis is very much significant to install the wind models, for that the wind speed plays a key role in obtained wind power. The wind power depends on wind speed across any region so we have made the wind speed observation across the coastal megacity of Pakistan for the wind turbine installation. The wind speed data is occupied from the World Bank site to explore wind model for the future power supply across Karachi of Pakistan. The wind speed factor is being an experiment by the 2015-2017 year. The wind parameter as wind speed is observed from April to December of 2015 as fig.3. Secondly, the wind parameter is 
investigated from January to December of 2016 in the two-phase as presented in figure.4-5. The reported model for the wind speed by the World Bank gives the consistent variation trend across the entire years. Hence the fluctuation is present in the wind speed. Similarly, the third experimentation of the year 2017 for wind speed is being calculated from January to April of 2017 as the state in fig.6. The observed model is employed for the future wind speed trend from the preceding 2015-17 year data of the World Bank. It is detected that the regular trend for each of the selected years is related to the next year so the perceived trend of wind speed is valid for the upcoming year, hence the wind speed availability indicates the installation of a wind turbine for the power generation across the coastal megacity of Pakistan. The wind speed accessibility for Pakistan especially Karachi is being tested in the fig.14. Hence from the experimental data, the coastal megacity contains the huge amount of the wind potential the planner need to explore this energy by installing a suitable quantity of the windmills for

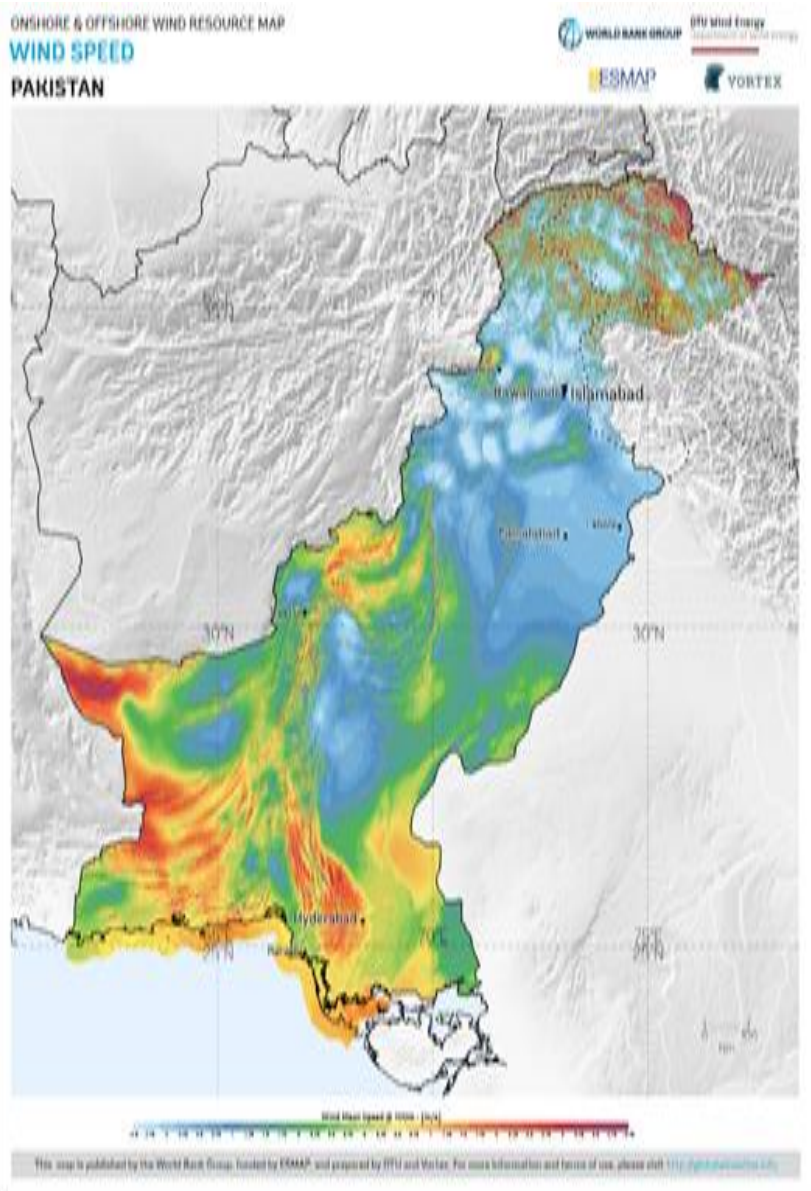

Fig.14. The wind map show the wind potentials availability across coastal mega city of Pakistan. Picture Source: onshore and offshore wind resource map World Bank Group site.

The solar irradiation calculation is very much important to install the solar models, for that the GHI play the main role to obtained solar assessability in the observed location. The GHI irradiation decides the future of the solar power across any of selected location. So we have select the GHI for the solar observation across Karachi of Pakistan. The GHI data is taken from the World Bank site and exploring on the excel to power generation.

find the evaluation solar model for the future power generation across the coastal megacity of Pakistan. The GHI parameter is observed by a yearly basis across 2015-2017. First, the GHI Irradiation is observed from April to December of 2015 as fig.7. Secondly the GHI observation from January to June of 2016 and July to December of 2016 as shown in figure.8-9. While looking at the models, as reported by the World Bank for GHI show the consistent trend across the entire years. Similarly, the third observation for the GHI is being calculated from January to April of 2017 as refer fig.10. The observed model is employed for the future GHI irradiation trend from the previous year data of the World Bank. It is observed that the consistent trend for each of the selected years is similar to the next year so the observed trend of GHI is also valid for the future assessment of the solar energy across the coastal megacity of Pakistan. The GHI availability for Pakistan especially Karachi is being examined in the fig.15. Hence from the observed data, the Karachi contains the enormous quantity of the solar potential the government essentially put an efforts to explore this energy by installing a proper capacity of the solar plant for energy generation.

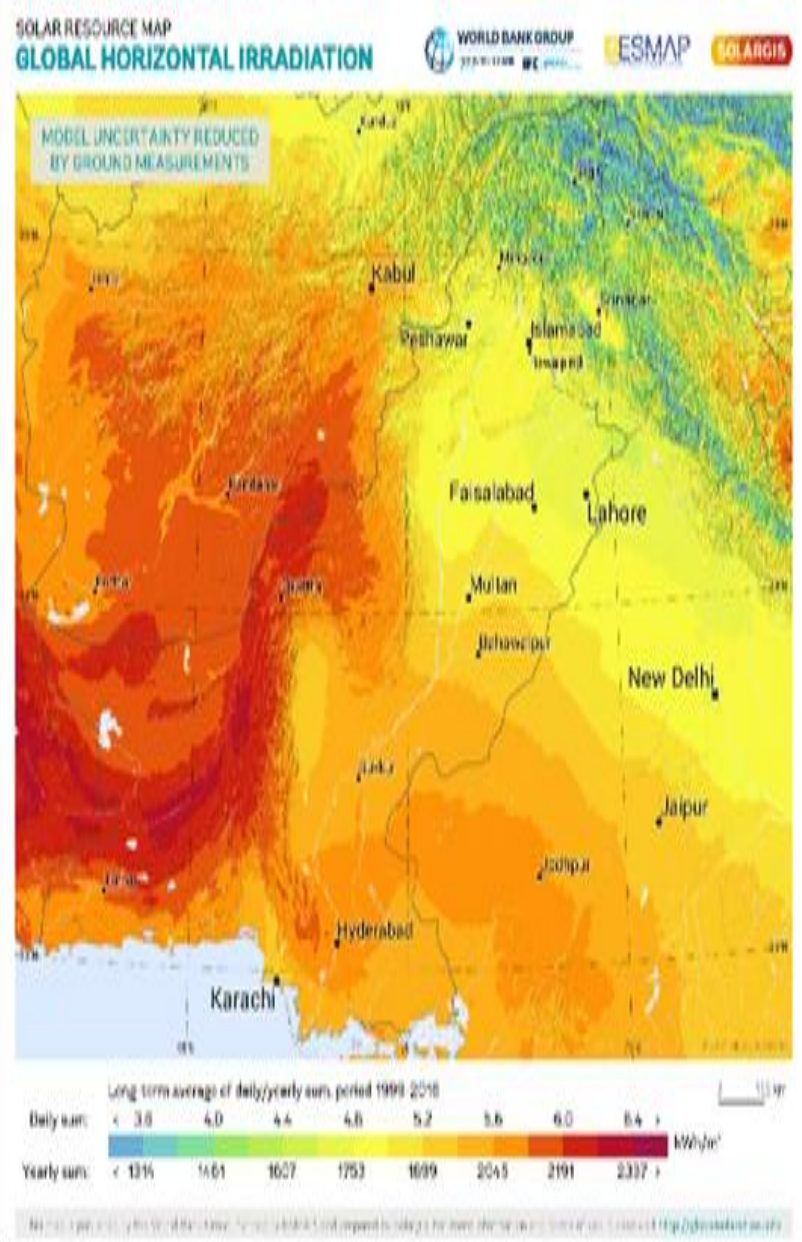

Fig.15. The solar map Resources expressing the GHI across coastal mega city, of Pakistan. Picture Source: Solar Atlas World Bank Group. 


\section{CONCLUSION}

Pakistan has enormous RE energy potential such as solar and wind but the country still uses fossil fuel. The main focus is on the evaluations of the GHI parameter of solar and wind speed of wind resources along with the yearly values provided by the World Bank. The solar parameter GHI play a significant role for the solar penal installation similarly the wind speed calculation is important for the installation of the windmill across the coastal megacity, of Pakistan. By observation of this research, planner needs to installation the $\mathrm{RE}$ project for the power generation in the coastal megacity due to abundant availability of the solar and wind energy resources.

\section{ACKNOWLEDGEMENTS}

The World Bank Group are acknowledge to make renewable energy data available for Pakistan

\section{REFERENCES}

1. A. Ali, D. B. Rahut, M. Imtiaz. Effects of Pakistan's energy crisis on farm households. Utilities Policy. Volume 59, 100930 (August 2019).

2. H. B. Khalil and S. J. H. Zaidi. Energy crisis and potential of solar energy in Pakistan. Renewable and Sustainable Energy Reviews. Volume 31, Pages 194-201(2014).

3. M. H. Baloch, S.T. Chauhdary, D. Ishaka, G. S. Kaloi, M. H Nadeem, W. A. Wattoo, T. Younas, H. T. Hamid. Hybrid energy sources status of Pakistan: An optimal technical proposal to solve the power crises issues. Energy Strategy Reviews. Volume 24, Pages 132-153 (April 2019).

4. F. M. Mirza, N. Fatim, K. Ullah. Impact of China-Pakistan economic corridor on Pakistan's future energy consumption and energy saving potential: Evidence from sectoral time series analysis. Energy Strategy Reviews. Volume 25, Pages 34-46 (August 2019).

5. S. Ahmed, A. Ali, D. Kumar, M. Z. Malik, A. H. Memon. China Pakistan Economic Corridor and Pakistan's energy security: A meta-analytic review. Energy Policy Volume 127, Pages 147-154 (April 2019).

6. Y. A. Solangi, Q. Tan, N. H. Mirjat, S. Ali. Evaluating the strategies for sustainable energy planning in Pakistan: An integrated SWOT-AHP and Fuzzy-TOPSIS approach. Journal of Cleaner Production Volume 236, 1117655 (November 2019).

7. H. Zameer and Y. Wang. Energy production system optimization: Evidence from Pakistan. Renewable and Sustainable Energy Reviews. Volume 82, Part 1, Pages 886-893 (February 2018).

8. T. Aized, M. Shahid, A. Ali. Bhatti, M. Saleem, G. Anandarajah. Energy security and renewable energy policy analysis of Pakistan. Renewable and Sustainable Energy Reviews Volume 84, Pages 155-169 (March 2018).

9. W. Uddin, Ayesh, K. Zeb, A. Haider, B. Khan, S. Islam, M. Ishfaq, I. Khan, M. Adil, H. J. Kim. Current and future prospects of small hydro power in Pakistan: A survey. Energy Strategy Reviews. Volume 24, Pages 166-177 (April 2019).

10. A. Ullah, Z, Neelum, S. Jabeen. Factors behind electricity intensity and efficiency: An econometric analysis for Pakistan. Energy Strategy Reviews. Volume 26, 100371 (November 2019).

11. U. Zafar, T. Rashid, A. A. Khosa, M. S. Khalil, M. Rashid. An overview of implemented renewable energy policy of Pakistan. Renewable and Sustainable Energy Reviews Volume 82, Part 1, Pages 654-665 (February 2018).

12. M. Shoaib, I, Siddiqui, S, Rehman, S. Khan, L. M. Alhems. Assessment of wind energy potential using wind energy conversion system. Journal of Cleaner Production. Volume 216, 10 Pages 346-360 (April 2019).

13. M. S. Nazir, A. J. Mahdi, M. Bilal, H. M. Sohail, N. Ali, H. M. N. Iqbal. Environmental impact and pollution-related challenges of renewable wind energy paradigm - A review. Science of The Total Environment. Volume 683, Pages 436-444 (15 September 2019).

14. B. Lin, M. Y. Raza. Analysis of energy related CO2 emissions in Pakistan. Journal of Cleaner Production. Volume 219, Pages
981-993 (10 May 2019).

15. Z. H. Hulio, W. Jiang, S. Rehman. Techno - Economic assessment of wind power potential of Hawke's Bay using Weibull parameter: A review. Energy Strategy Reviews Volume 26, 100375 (November 2019).

16. M. Shahid, S. A. Kalhoro, D. Ara, N. Bano, R. Perween. Wind and solar energy Potentials around Southern Sindh \& Southern Baluchistan provinces, especially Karachi of Pakistan. 3C Tecnología. pp. 116-141. doi http://dx.doi.org/10.17993/3ctecno.2019. 2.116-141 (2019).

17. O. L. Lapeña and R. P. Areny. Solar energy radiation measurement with a low-power solar energy harvester. Computers and Electronics in Agriculture Volume 151, Pages 150-155 (August 2018).

18. Z. R. Tahir and M. Asim. Surface measured solar radiation data and solar energy resource assessment of Pakistan: A review. Renewable and Sustainable Energy Reviews. Volume 81, Part 2, Pages 2839-2861 (January 2018).

19. A. Ashfaq and A. Ianakiev. Features of fully integrated renewable energy atlas for Pakistan; wind, solar and cooling. Renewable and Sustainable Energy Reviews. Volume 97, Pages 14-27 (December 2018).

20. S. A. Kalhoro, S. H. A. Musvi, S. Ali, S. Rahoojo, A. Nawaz. An economical and relatively efficient implementation of the Real-Time Solar Tracking System. 3C Tecnología. pp. 68-99. doi: http://dx.doi.org/10.17993/3ctecno.2019. 2.68-99 (2019).

21. M. Kamran, M. R. Fazal, M. Mudassar. Towards empowerment of the renewable energy sector in Pakistan for sustainable energy evolution: SWOT analysis. Renewable Energy. Volume 146, Pages 543-558 (February 2020).

22. A. Wahab, A. Hassan, M. A. Qasim, H. M. Ali, H. Babar, M. U. Sajid. Solar energy systems - Potential of nanofluids. Journal of Molecular Liquids Volume 289, 111049 (1 September 2019).

23. H. B. Khalil and S. J. H. Zaidi. Energy crisis and potential of solar energy in Pakistan. Renewable and Sustainable Energy Reviews. Volume 31, Pages 194-201 (March 2014).

24. A,. Sadiqa, A. Gulagi, C. Breyer. Energy transition roadmap towards $100 \%$ renewable energy and role of storage technologies for Pakistan by 2050. Energy. Volume 147, Pages 518-533 (15 March 2018)

25. O. Rauf, S. Wang, P. Yuan, J. Tan. An overview of energy status and development in Pakistan. Renewable and Sustainable Energy Reviews. Volume 48, Pages 892-931 (August 2015).

26. S. R. Shakeel, J. Takala, W. Shakeel. Renewable energy sources in power generation in Pakistan. Renewable and Sustainable Energy Reviews. Volume 64, Pages 421-434 (October 2016).

27. J. McCarthy, J. Thatcher. Visualizing new political ecologies: A critical data studies analysis of the World Bank's renewable energy resource mapping initiative. Geoforum. Volume 102, Pages 242-254 (June 2019).

28. J. Urpelainen. RISE to the occasion? A critique of the World Bank's Regulatory Indicators for Sustainable Energy. Energy Research \& Social Science. Volume 39, Pages 69-73 (May 2018). 